\title{
Effects of Red Ginseng on Exercise Capacity and Peripheral Fatigue in Mice
}

\author{
Daehyun Kima ${ }^{a}$, Byounggwan Lee ${ }^{a}$, Heejin Kim ${ }^{\circledR}$, Mikyung Kim ${ }^{a}$

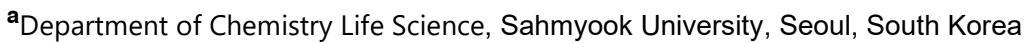 \\ bUimyung Research Institute for Neuroscience, Sahmyook University, Seoul, South Korea
}

\begin{abstract}
Objective: Fatigue can decrease both quality of life and work efficiency. Ginseng is one of the most popular herbal treatments for improving personal health, with applications in treating fatigue. However, the exact mechanisms of anti-fatigue effects are still unclear. Thus, we investigated the effect of red ginseng powder (RGP) on exercise capacity and peripheral fatigue using both behavioral and molecular experiments in mice.
\end{abstract}

Design: Four-groups behavioral and molecular experiment.

Methods: Male 6-weeks-old ICR mice were treated with distilled water, 100, and $200 \mathrm{mg} / \mathrm{kg}$ RGP for 5 days via oral administration. The exercise capacity of each animal group was measured by locomotor activity, rota-rod, hanging wire, and cold swimming tests. Additionally, after performing the treadmill to induce fatigue, lactate expression and molecular experiments were investigated using mice gastrocnemius.

Results: Mice treated with RGP exhibited increased exercise capacity in the behavioral tests. Additionally, RGP induced a dose-dependent decrease in lactate levels after high-intensity exercise, and Monocarboxylate transporter (MCT) 4 expression increased in groups treated with RGP. However, there was no significant change in MCT1.

Conclusions: These results suggest that RGP exerts several anti-fatigue properties by lower lactate and improved exercise capacity. Increased MCT4 expression may also affect lactate transport. Thus, this study suggests that the anti-fatigue properties of RGP might be associated with MCT4 activity.

Key Words: Red ginseng, Fatigue, Monocarboxylate transporter, Lactate, Exercise capacity

\section{Introduction}

Fatigue refers to the feeling of tiredness and a lack of energy [1]. Many studies have reported that the majority of people suffer from health problems related to fatigue [2,3]. Fatigue after exhaustive exercise can be divided into two types: peripheral muscle fatigue (local fatigue of the muscles involved in the exercise) and central fatigue (the central nervous system fails to compensate for physiological disturbances) [4,5]. Peripheral muscle fatigue caused by physical activity is primarily caused by the accumulation of lactate when anaerobic glycolysis occurs in the muscle [6]. Lactate is one of the major products from the oxidation of pyruvate by lactate dehydrogenase during glycolysis and lactate circulation is promoted by the proton-linked monocarboxylate transporter (MCT) [7,8]. The MCT family has 14 members all of whom are located in the cell membrane and function to transport monocarboxylate via single transport in and out of the cell. MCT1 is mainly present in the oxidative muscles and carries substances into the cells. MCT4 is mainly present in the fast glycolytic muscle and transports the produced substance to the outside of the cell [9].

Received: Jun 6, 2021 Revised: Jun 17, 2021 Accepted: Jun 18, 2021

Corresponding author: Mikyung Kim (ORCID https://orcid.org/0000-0003-0524-1658)

Department of Chemistry Life Science, Sahmyook University

815, Hwarang-ro, Nowon-gu, Seoul, 01795 Republic of Korea [01795]

Tel: + 82-2-3399-1716 Fax: + 82-2-3399-1729 E-mail: mkkim@syu.ac.k

This is an Open-Access article distributed under the terms of the Creative Commons Attribution Non-Commercial License (http://creativecommons.org/licenses/ by-nc/4.0) which permits unrestricted non-commercial use, distribution, and reproduction in any medium, provided the original work is properly cited.

Copyright $(2021$ Korean Academy of Physical Therapy Rehabilitation Science 
Ginseng root is one of the traditional medical treatment used in many Asian countries to promote health and treat diseases [10]. Red ginseng, a product produced by the processing of ginseng plants, has been studied with a focus on various physiological functions, including anti-fatigue and anti-inflammatory effects [11,12]. The mechanism of the anti-fatigue properties of red ginseng remainsunclear, although many studies have reported the anti-fatigue properties of these compounds. Thus, this study investigated the anti-fatigue effect of red ginseng after exhausting exercise. We measured physical exercise capacity, such as locomotor activity, motor balance, and swimming and confirmed the reduction in the fatigue of treated animalsby measuring lactate accumulation after exhausting exercise and measuring the level of expression of mRNA and protein related to MCT1 and MCT4.

\section{Materials and methods}

\section{Materials}

Six-year-old red ginseng powder (RGP) (ginsenoside $\mathrm{Rg} 1+\mathrm{Rb} 1+\mathrm{Rg} 3 \quad 6 \quad \mathrm{mg} / \mathrm{g}$ ) was obtained from Jeonggwanjang (Seoul, Korea), dissolved in distilled water (DW) $\left(22 \pm 2{ }^{\circ} \mathrm{C}\right)$ and administered orally to experimental mice. This administration was performed 30 min before any evaluations and continued for 5 days.

\section{Animals and treatments}

Male 6-week-old ICR mice (29-34 g) were obtained from Hanlim Laboratory Animals Company. Animals were group housed in an animal room with controlled conditions (light on at 7 am with a 12-hour contrast cycle, a temperature of $22 \pm 2{ }^{\circ} \mathrm{C}$, and humidity at $55 \pm 5 \%$ ). Food and water were freely available and after a 1-week adaptation period, the animals were treated with DW, 100, and $200 \mathrm{mg} / \mathrm{kg}$ RGP for 5 days via oral administration. Animal treatment and maintenance were carried out in accordance with the Principles of Laboratory Animal Care (National Institutes of Health publication no. 85-23, revised 1985) and the Animal Care and Use Guidelines of Sahmyook University (Seoul, Korea SYUIACUC2020-003).

\section{Locomotor activity}

Changes in locomotor activity were measured using the open field tests (OFT) and the EthoVision system (ver. 3.1, Noldus Information Technology, Netherlands). Each animal was treated with DW or RGP 100, or $200 \mathrm{mg} / \mathrm{kg}$ for 5 days and then placed in the observation equipment, a black Plexiglas box $(42 \times 42 \times 42 \mathrm{~cm})$. The total distance moved $(\mathrm{cm})$ and movement duration $(\mathrm{s})$ were monitored over a $10 \mathrm{~min}$ after $2 \mathrm{~min}$ of habituation.

\section{Rota-rod test}

Experimental mice were placed to run forward on a horizontal bar rotating at a speed of $36 \mathrm{rpm}$ (47650, UgoBasile, Italy). The latency time to the first fall and the falling frequency for $10 \mathrm{~min}$ were measured manually. The experimental mice were habituated to the equipment once a day for 2 days before the experiment for $3 \mathrm{~min}$

\section{Hanging wire test}

The hanging wire test evaluates grip retention and serves as an indicator for fatigue and neuromuscular damage [13]. After placing the experimental mice to hold the horizontal wire (diameter $5 \mathrm{~mm}$, length 150 $\mathrm{cm}, 80 \mathrm{~cm}$ above the floor) using their front paws, hind paws, and tail, the latency time to the first fall and falling frequency were measured for $10 \mathrm{~min}$. The experimental mice were habituated to hang from the wire for $3 \mathrm{~min}$ the day before the start of the experiments.

\section{Cold swimming test}

The animals were pressured to swim in cold water maintained at $15 \pm 1{ }^{\circ} \mathrm{C}$. The experimental setup included a rectangular water tank (width $22.5 \mathrm{~cm}, 40$ $\mathrm{cm}$, height $18 \mathrm{~cm}$ ) made of plastic, filled with $11 \mathrm{~cm}$ of water. Mice were forced to swim until they were exhausted and drowned. Time to swim in the cold water was manually recorded using a stopwatch. After the experiment, the mice were wiped dry with a paper towel. 


\section{Lactate levels after exhausting treadmillexercise}

High-intensity training was conducted using an inclined treadmill [14]. Animals were treated with DW, RGP 100, or $200 \mathrm{mg} / \mathrm{kg}$ once a day for 5 days before exercise. On the day of exercise, DW or RGP was administered $30 \mathrm{~min}$ prior to exercise and the exercises moved from low to high intensity over a 34 min period. To create a high-intensityexercise environment, the slope of the treadmill was set at $13^{\circ}$. Treadmill adaptation was performed at $0 / 3 / 15 / 20 / 25$ $\mathrm{m} / \mathrm{min}$ for $5 / 2 / 2 / 2 / 3 \mathrm{~min}$ on the day of exercise, and no electric shock was applied at this stage. After this exercise was conducted, the animals received an additional electric shock $(3 \mathrm{mV}-4 \mathrm{mV})$ at 30/35/40 and $45 \mathrm{~m} / \mathrm{min}$ for, $5 / 5 / 5$, and $5 \mathrm{~min}$. After exercise, the lactate levels in each animal were measured using Accutrend Plus (05050472, Roche Diagnostics, Germany). Additionally, the lactate levels of the drug-naïve and no-exercise groups (CON) were measured to confirm the background lactate level in these animals.

\section{qRT-PCR}

The expression levels of Mct1 and Mct4 in the gastrocnemius collected after the treadmill experiment were measured. Total RNA was extracted using TRIzol (301-001, Geneall Biotechnology, Korea) as described in the manufacturer's instructions. This RNA was then further purified using a Hybrid-R ${ }^{\mathrm{TM}}$ kit (305-101, Geneall Biotechnology, Korea) and the total RNA concentration was determined using a Colibri Spectrometer (5410012212-2012 Titertek-Berthold, Germany). AccuPower ${ }^{\circledR}$ CycleScript RT PreMix (K-2047-B, Bioneer, South Korea) was used to produce cDNA according to the manufacturer's instructions, and amplified using a set of custom sequence-specific primers (Cosmogentech, South Korea): Mct1 forward (5'-TTG TCT GTC TGG CGG CTT GAT CG-3') and reverse (5'-GCC CAA GAC CTC CAA TAA CAC CAA TGC -3'); Mct4 forward (5'- ACG GCT GGT TTC ATA ACA GG -3') and reverse (5'- CCA ATG GCA CTG GAG AAC TT -3'). SYBR green reagent (SRH83-M40H, Solgent, South Korea) was used for the detection. The qRT-PCR reactions were performed in triplicate to evaluate $M c t 1$ and Mct4. The cycling conditions were as follows: $95{ }^{\circ} \mathrm{C}$ for $15 \mathrm{~min}, 95{ }^{\circ} \mathrm{C}$ for $20 \mathrm{sec}, 60^{\circ} \mathrm{C}$ for $40 \mathrm{sec}, 72{ }^{\circ} \mathrm{C}$ for $30 \mathrm{sec}$, and $95{ }^{\circ} \mathrm{C}$ for $15 \mathrm{sec}$. All results were analyzed using the ${ }^{\Delta 4} \mathrm{Ct}$ method $\mathrm{Ct}$ is defined as the threshold cycle.

\section{Protein extraction and western blot}

The amount of MCT1 and MCT4 were measured by western blot. MCT1 and MCT4 are transporters that transport lactate which is measured as a biomarker for fatigue. After the treadmill experiment, the gastrocnemius muscles of the mice were isolated, and stored at -80 ${ }^{\circ} \mathrm{C}$. Samples were homogenized in cold homogenization buffer (RIPA buffer, Biosesang, South Korea) containing phosphatase inhibitor and protease inhibitors and the homogenates were centrifuged for $20 \mathrm{~min}$ at 16,000 $\mathrm{RCF}$ at $4{ }^{\circ} \mathrm{C}$ and the supernatant was used. Proteins were separated on a $10 \%$ SDS/PAGE gel in the sequence of 80 volts for $15 \mathrm{~min}$ and 120 volts for $60 \mathrm{~min}$. The separated proteins were transferred to nitrocellulose membranes and blocked with blocking buffer (5\% bovine serum albumin dissolved in TBST buffer) for $60 \mathrm{~min}$. Membranes were incubated with primary antibodies [anti-MCT1 polyclonal Ab (MBS8308108), anti-MCT4 monoclonal Ab (MBS9702456), and anti-beta-actin ( $\beta$-Actin) mouse monoclonal $\mathrm{Ab}$ (A5441)] overnight at $4{ }^{\circ} \mathrm{C}$, then washed three times in TBST for $5 \mathrm{~min}$ to remove the remaining primary antibody and incubated with anti-rabbit (1:3000) or anti-mouse secondary antibodies (1:5000) for $60 \mathrm{~min}$ at room temperature. Each protein was detected using the ChemiDoc Imaging System (Image Lab software version 6.0, Bio-Rad, USA) after three final washes with TBST and exposure to an enhanced chemiluminescence (Clarity Western ECL) reagent. Values were normalized against $\beta$-actin and protein expression was compared to that of the control group.

\section{Statistical analysis}

All data are expressed as the mean \pm standard error of the mean (SEM). Statistical analysis was performed using one-way analysis of variance (ANOVA) followed by a Bonferroni's post-hoc test when significant group differences were observed. $\mathrm{p}<0.05$ was considered statistically significant. 
A

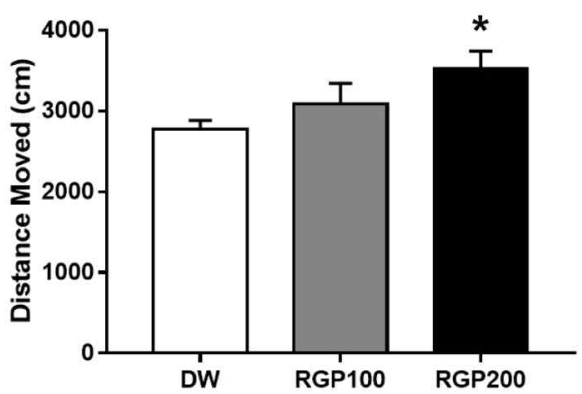

C

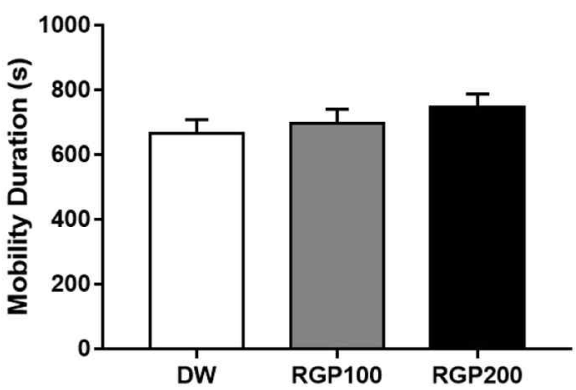

B

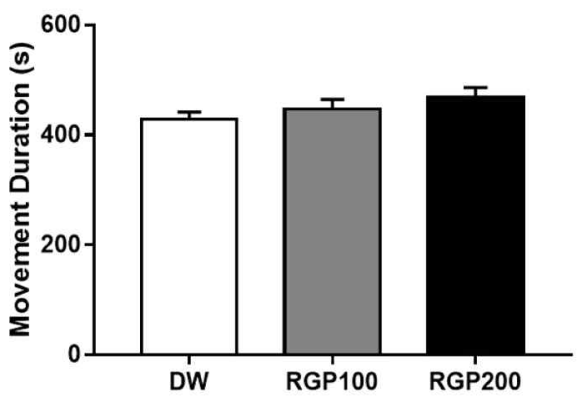

Figure 1. Effect of RGP on locomotor activity and mobility time

(A-B) Effects of 5 days of RGP treatment on locomotor activity in mice (n=9-10). Each bar represents the mean \pm SEM value for the total distance moved (A) and movement duration (B) over a 10 min period. (C) Effects of RGP on mobility duration cold water swimming in mice $(\mathrm{n}=9-10)$.

*significantly different from control group, ${ }^{*}(\mathrm{p}<0.05)$.

DW: group treated with DW and exercised, RGP100: group treated with $100 \mathrm{mg} / \mathrm{kg} \mathrm{RGP}$ and exercised, RGP200: group treated with $200 \mathrm{mg} / \mathrm{kg}$ RGP and exercised.

\section{RESULT}

\section{Effect of RGP on locomotor activity in mice.}

Figure. 1 compares the locomotor activity between the various treatment groups. One-way ANOVA found asignificant difference in the distance moved in each group $[\mathrm{F}(2,24)=3.62, \mathrm{p}<0.05$; Figure. 1A]. Bonferroni's post-hoc test showed that mice treated with RGP200 demonstrated a significant increase in distance moved compared to the control group, and mice treated with RGP100 showed a trend of increasing movement when compared to the control. There were no significant differences in the overall duration of the movement $[F(2,24)=1.6, p=0.22$; Figure. 1B]. However, there was a slight trend to increased movement time for treated animals, that also appears to be dose dependent.

\section{Effect of RGP on cold water swimming in mice.}

There were no significant difference in the level of mobility duration $[F(2,25)=0.95, p=0.399$; Figure. 1C $]$ between any of the groups, but there was a general trend for increasing mobility time in the RGP groups, which was similar to the locomotor activity results.

\section{Effect of RGP on the rota-rod and hanging wire tests}

No significant differences were observed in latency time $[\mathrm{F}(2,22)=1.86, \mathrm{p}=0.178$; Figure. $2 \mathrm{~A}]$ or falling frequency $[\mathrm{F}(2,24)=1.15, \mathrm{p}=0.331$; Figure. $2 \mathrm{~B}]$ in the rota-rod motor balance and coordination tests. However, there was a trend toward increased latency time and decreased falling frequency in the animals treated with RGP. Thus, we went on to conduct the wire tests to further evaluate the effect of RGP 
A

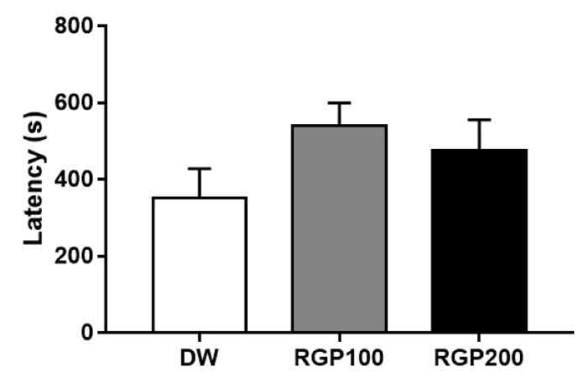

C

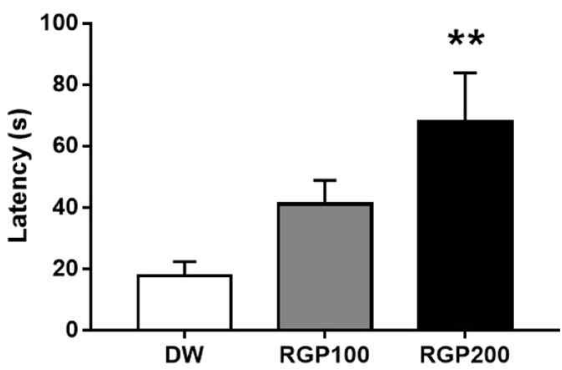

B

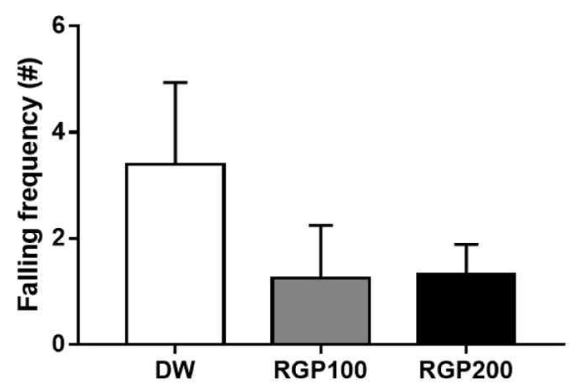

D

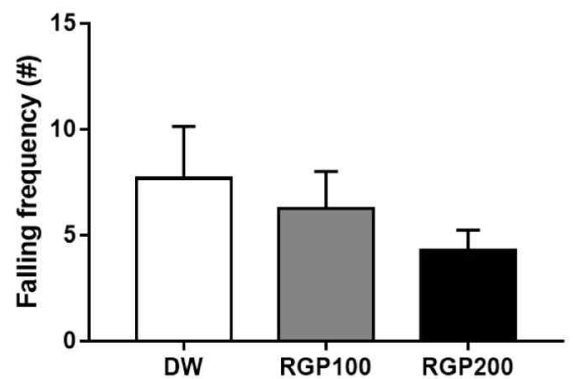

Figure 2. Effects of RGP on motor balance and coordination

(A-B) Effects of 5 days of RGP treatment on rota-rod tests, evaluating motor balance and coordination (n=9-10). Each bar represents the mean \pm SEM for latency time (A) until the mice first fall and falling frequency (B) over rota-rod $10 \mathrm{~min}$. (C-D) Effects of 5 days of RGP treatment on limb strength and balance during a hanging wire test (n=10). Each bar represents the mean \pm SEM of the first falling time (C) and falling frequency (D) over $10 \mathrm{~min}$.

*significantly different from control group, $* *(\mathrm{p}<0.01)$.

DW: group treated with DW and exercised, RGP100: group treated with $100 \mathrm{mg} / \mathrm{kg}$ RGP and exercised, RGP200: group treated with $200 \mathrm{mg} / \mathrm{kg}$ RGP and exercised.

treatment on motor balance and coordination. The hanging wire test is used to measure both limb strength and balance after treatment of materials [15]. We found significant differences between the DW and RGP groups $[\mathrm{F}(2,23)=5.74, \mathrm{p}<0.01$; Figure. $2 \mathrm{C}]$. The post-hoc test showed that the latency time of mice treated with RGP200 increased significantly $(\mathrm{p}<0.01)$ when compared to DW treatment, and there was a trend of decreased falling frequency in the RGP groups, which also demonstrated some degree of dose dependence $[F(2,26)=0.80, p=0.459$; Figure. 2D $]$.

\section{Effect of RGP on fatigue in mice.}

There were significant differences in the lactate levels $[F(3,34)=8.52, p<0.001$; Figure. $3 \mathrm{~A}]$ between the groups. Post-hoc tests showed that the animals treated with DW produced increased levels of lactate after exhausting exercise on the treadmill when compared to the CON group that did not exercise $(\mathrm{p}<0.001)$ while the animals treated with RGP200 did not significantly increase the lactate level after exercise $(\mathrm{p}<0.11)$.

\section{Effect of RGP on Mct1 and Mct4 mRNA expression in mice muscle after exercise.}

Each group displayed significantly different levels of both $\operatorname{Mct1}[\mathrm{F}(3,19)=3.20, \mathrm{p}<0.05$ Figure. 4A] and Mct4 $[\mathrm{F}(3,19)=4.83, \mathrm{p}<0.05$ Figure. 4B] mRNA expression in the gastrocnemius muscles after exhaustive exercise. Post-hoc tests showed that 


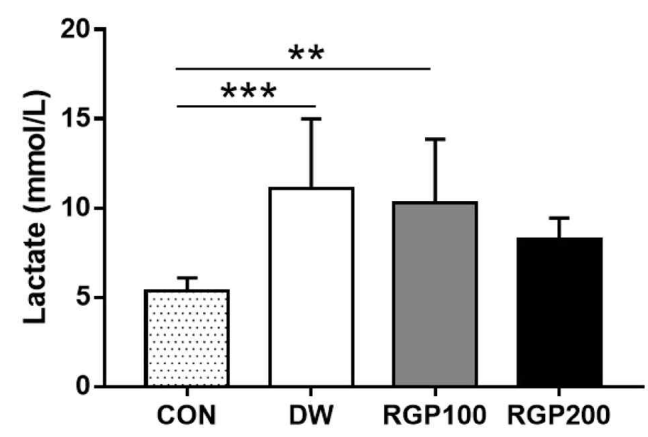

Figure 3. Effects of RGP on lactate levels after exhausting exercise

Effects of 5 days of RGP treatment on fatigue in mice $(n=9-10)$. Each bar represents the mean \pm SEM. Lactate levels were measured following 34 min of treadmill exercise.

*significantly different from control group, $* *(\mathrm{p}<0.01), * * *(\mathrm{p}<0.001)$.

CON: group with no treatment and no exercise, DW: group treated with DW and exercised, RGP100: group treated with $100 \mathrm{mg} / \mathrm{kg}$ RGP and exercised, RGP200: group treated with $200 \mathrm{mg} / \mathrm{kg}$ RGP and exercised.

A

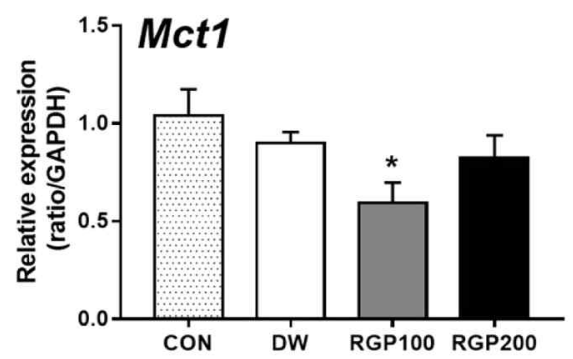

B

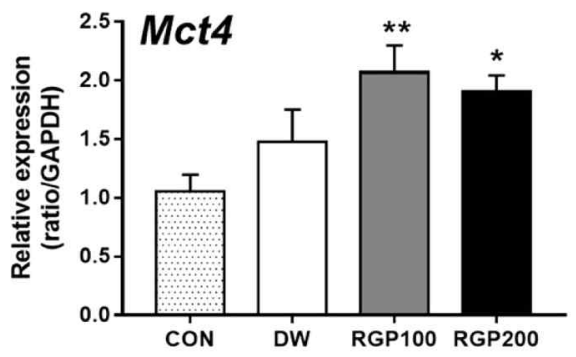

Figure 4. Effects of RGP on the mRNA levels of Mct1 and Mct4 after exhausting exercise

Effects of RGP treatment on Mct1 (A) and Mct4 (B) mRNA expression in gastrocnemius muscles of exhausted mice as confirmed by qRT-PCR $(n=6)$.

Each bar represents the mean \pm SEM.

*significantly different from the control group, $*(\mathrm{p}<0.05), * *(\mathrm{p}<0.01)$.

CON: group with no treatment and no exercise, DW: group treated with DW, RGP100: group treated with $100 \mathrm{mg} / \mathrm{kg}$ RGP, RGP200: group treated with $200 \mathrm{mg} / \mathrm{kg}$ RGP.

RGP100 treatment demonstrated a significant decrease in Mct1 mRNA expression $(\mathrm{p}<0.05)$ compared to the CON group (Figure. 4A). However, one-way ANOVA failed to find any significant differences between the other groups. For Mct4, RGP100 $(\mathrm{p}<0.01)$ and RGP200 $(\mathrm{p}<0.05)$ were both significantly increased when compared to the CON group (Figure. 4B). DW exhibited a trend of increasing MCT4 expression compared to the CON group. However, these differences were not statistically significant $(p=0.35)$.
Effect of RGP on MCT1 and MCT4 protein expression in mice muscle.

There was no significant difference in MCT1 expression $[\mathrm{F}(3,18)=0.76, \mathrm{p}=0.5308$ Figure. $5 \mathrm{~A}]$ between the groups. For MCT4 expression levels, one-way ANOVA found significant differences between groups $[\mathrm{F}(3,18)=6.64, \mathrm{p}<0.001 ;$ Figure. 5B]. Bonferroni post-tests indicated that MCT4 expression levels in RGP100 $(\mathrm{p}<0.05)$ and RGP200 $(\mathrm{p}<0.01)$ increased 
A

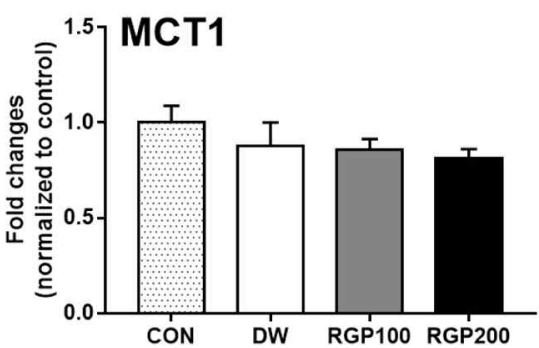

B

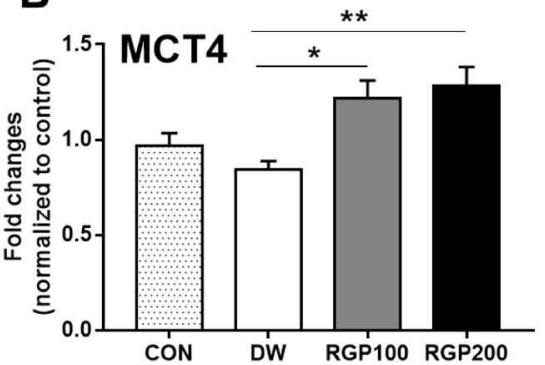

CON

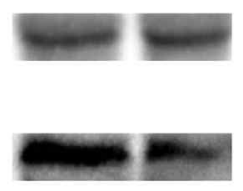

MCT1

MCT4

\section{B-actin}

DW
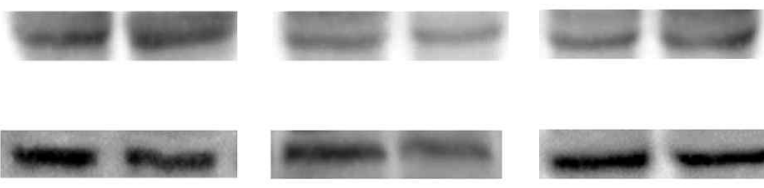

Figure 5. Effects of RGP on the MCT1 and MCT4 protein levels after exhausting exercise exercise mice confirmed by western blot $(n=6)$.

Each bar represents the mean \pm SEM.

*significantly different compared to the DW group, $*(\mathrm{p}<0.05), * *(\mathrm{p}<0.01)$.

CON: group with no treatment and noexercise, DW: group treated with DW, RGP100: group treated with RGP at 100 $\mathrm{mg} / \mathrm{kg}$, RGP200: group treated with RGP at $200 \mathrm{mg} / \mathrm{kg}$.

after exhaustive exercise compared to DW. In addition, their expression levels exhibited a trend of increase compared to the CON after exercise, although there were no significant differences in DW compared to CON ( $>0.99)$.

\section{Discussion}

The goal of this study was to investigate the effect of RGP on fatigue in mice using behavioral tests and molecular experiments. This study found that RGP has various anti-fatigue properties, as evidenced by increased exercise capacity in behavioral tests such as OFT, rota-rod tests, and hanging wire tests, as well as decreased blood lactate levels. The anti-fatigue properties of RGP are probably mediated through increased MCT4 activity in the gastrocnemius muscles of mice.
Previous studies have reported that anti-fatigue activity can be interpreted as an increase in exercise capacity [16,17]. For example, decreased locomotor activity in the OFT was interpreted as a sign of increased fatigue [18]. Hsiao et al. reported that micetreated with herbal mixtures including ginseng exhibited increased swimming time in swimming tests and anti-fatigue properties [19]. Mice treated with ginseng polysaccharide fraction or metabolized fractions demonstrated increases in swimming duration and riding time in the swimming and rota-rod tests, respectively. This suggests that RGP supplementation has a positive effect on fatigue as demonstrated by improvements in exercise capacity.

Lactate can be used as a biochemical indicator of muscle fatigue following exercise [6,20,21]. Lactate removal from tissues reduces peripheral nerve muscle 
fatigue and plays an important role in preserving muscle function [22]. Recovery after high-intensity exercise is affected by the rate of blood lactate reduction [23]. Our results reveal a significant decrease in lactate levels following treatment with RGP. MCT is a family of transporters that transport lactate $[7,8]$. Increased expression of MCT1 and MCT4 induces an increase in the rate of lactate transport and circulation [24,25]. MCT1 aids in the cellular adsorption of lactate while MCT4 releases lactate into the blood vessels [9]. The amount of MCT1 and MCT4 differs depending on the muscle type, and the type may be easily changed by different stimulation $[9,26]$. It has been suggested that MCT4 is mainly expressed in white muscles [25,27] and hypoxia may increase its expression [28]. Supramaximal experiments produce glycolysis [29]. Taken together, low-oxygen high-intensity training may be associated with the energy consumption of white muscles. Mct1 and Mct4 appear to be rapidly upregulated metabolic gene [26]. In our molecular experiments, Mct1 and MCT1 showed a tendency to decrease slightly, while both Mct4 and MCT4 showed a significant increase following exercise in animals treated with RGP compared to the DW group. Thomas and colleagues suggested that MCT1 and MCT4 contents were altered by acute or chronic exercise, which induced alteration of lactate levels [30]. Both MCT1 and MCT4 increased after exhaustive swimming in rats treated with sildenafil citratewhich presented with reduced lactate levels in their blood [31]. The expression of MCT4 and GLUT4 increase during heavy intermittent cyclical exercise, but there is no significant change in MCT1 expression [32]. However, other studies have reported decreased MCT1 and MCT4 expression levels in human skeletal muscle without any treatments after high-intensity exercise [33,34]. Taken together these results suggest that MCT1 and MCT4 might play a role in regulating lactate levels in the blood. This study found increased MCT4 expression and decreased lactate in animals treated with RGP. The results of this study suggest that the high level of lactate expression after exhaustive exercise might be decreased through the increased expression of MCT4 rather than MCT1, and that MCT4 may be a major regulator of lactate transport during high-intensity exercise in animals treated with
RGP. RGP may influence exercise capacity and MCT4 activity.

In conclusion, this study found that RGP has anti-fatigue properties, as evidenced by an increase in exercise capacity, lower blood lactate levels, and an increase in Mct4 and MCT4 contentsin the gastrocnemius muscle of mice after RGP treatment. Based on these results, the anti-fatigue properties of RGP may be associated with increased MCT4 activity.

\section{Conflict of interest}

The authors confirm that they do not have any conflicts of interest.

\section{Acknowledgments}

This study was supported by the National Research Foundation (NRF) funded by the Korea government (NRF-2019R1A6A3A01095209).

\section{Reference}

1. Schwartz JE, Jandorf L, Krupp LB. The measurement of fatigue: a new instrument. J Psychosom Res. 1993;37:753-62.

2. Afari N, Buchwald D. Chronic fatigue syndrome: a review. Am J Psychiatry. 2003;160:221-36.

3. Pawlikowska T, Chalder T, Hirsch SR, Wallace P, Wright DJ, Wessely SC. Population based study of fatigue and psychological distress. BMJ. 1994;308:763-6.

4. Enoka RM. Muscle fatigue - from motor units to clinical symptoms. J Biomech. 2012;45:427-33.

5. Paillard T. Effects of general and local fatigue on postural control: A review. Neurosci Biobehav Rev. 2012;36:162-76.

6. Josef F. Biomarkers of peripheral muscle fatigue during exercise. BMC Musculoskelet Disord. 2012;13:1-13.

7. Enoki T, Yoshida Y, Hatta H, Bonen A. Exercise training alleviates MCT1 and MCT4 reductions in heart and skeletal muscles of STZ-induced diabetic rats. J Appl Physiol. 2003;94:2433-8.

8. Halestrap AP, Price NT. The proton-linked monocarboxylate transporter (MCT) family: structure, function and regulation. Biochem J. 1999;343:281-99.

9. Bonen A. The expression of lactate transporters 
(MCT1 and MCT4) in heart and muscle. Eur $\mathrm{J}$ Appl Physiol. 2001;86:6-11.

10. Wang CZ, Yuan CS. Potential role of Ginseng in the treatment of colorectal cancer. Am J Chin Med. 2008;36:1019-28.

11. Arring NM, Millstine D, Marks LA, Nail LM. Ginseng as a Treatment for Fatigue: A Systematic Review. J Altern Complement Med. 2018;24:624-33.

12. Baek KS, Yi YS, Son YJ, Yoo S, Sung NY, Kim $\mathrm{Y}$, et al. In vitro and in vivo anti-inflammatory activities of Korean red Ginseng-derived components. J Ginseng Res. 2016;40:437-44.

13. Ray MA, Trammell RA, Verhulst S, Ran S, Toth LA. Development of a mouse model for assessing fatigue during chemotherapy. Comp Med. 2011;61:119-30.

14. Thomas C, Bishop D, Moore-Morris T, Mercier J. Effects of high-intensity training on MCT1, MCT4, and NBC expressions in rat skeletal muscles: influence of chronic metabolic alkalosis. Am J Physiol Endocrinol Metab. 2007;293:E916-22.

15. Bharti M, Fudong L, Yan X, Rebecca P, Jun L, Louise M. Functional recovery in aging mice after experimental stroke. Brain Behav Immun. 2011;25:1689-700.

16. Gosker HR, Schols AMWJ. Fatigued muscles in COPD but no finishing line in sight. Eur Respir J. 2008;31:693-4.

17. Rainoldi A, Gazzoni M, Merletti R, Minetto MA. Mechanical and EMG responses of the vastus lateralis and changes in biochemical variables to isokinetic exercise in endurance and power athletes. $\mathrm{J}$ Sports Sci. 2008;26:311-9.

18. Ohba T, Domoto S, Tanaka M, Nakamura S, Shimazawa M, Hara H. Myalgic encephalomyelitis/chronic fatigue syndrome induced by repeated forced swimming in mice. Biol Pharm Bull. 2019;42:1140-5.

19. Hsiao CY, Hsu YJ, Tung YT, Lee MC, Huang CC, Hsieh CC. Effects of Antrodia camphorata and panax ginseng supplementation on anti-fatigue properties in mice. J Vet Med Sci. 2018;80:284-91.

20. Izquierdo M, González-Izal M, Navarro-Amezqueta I, Calbet JAL, Ibañez J, Malanda A, et al. Effects of strength training on muscle fatigue mapping from surface EMG and blood metabolites. Med Sci
Sports Exerc. 2011;43:303-11.

21. Strojnik V, Komi P V. Fatigue after submaximal intensive stretch-shortening cycle exercise. Med Sci Sports Exerc. 2000;32:1314-9.

22. White GE, Wells GD. The effect of on-hill active recovery performed between runs on blood lactate concentration and fatigue in alpine ski racers. J Strength Cond Res. 2015;29:800-6.

23. Ma GD, Chiu CH, Hsu YJ, Hou CW, Chen YM, Huang CC. Changbai mountain ginseng (Panax ginseng C.A. Mey) extract supplementation improves exercise performance and energy utilization and decreases fatigue-associated parameters in mice. Molecules. 2017;22:237.

24. Enoki T, Yoshida Y, Lally J, Hatta H, Bonen A. Testosterone increases lactate transport, monocarboxylate transporter (MCT) 1 and MCT4 in rat skeletal muscle. J Physiol. 2006;577:433-43.

25. Juel G, Halestrap AP. Lactate transport in skeletal muscle - Role and regulation of the monocarboxylate transporter. J Physiol. 1999;517:633-42.

26. Coles L, Litt J, Hatta H, Bonen A. Exercise rapidly increases expression of the monocarboxylate transporters MCT1 and MCT4 in rat muscle. J Physiol. 2004;561:253-61.

27. Manning Fox JE, Meredith D, Halestrap AP. Characterisation of human monocarboxylate transporter 4 substantiates its role in lactic acid efflux from skeletal muscle. J Physiol. 2000;529:285-93.

28. Ullah MS, Davies AJ, Halestrap AP. The plasma membrane lactate transporter MCT4, but not MCT1, is up-regulated by hypoxia through a HIF-1 $\alpha$-dependent mechanism. J Biol Chem. 2006;281:9030-7.

29. Thomas C, Perrey S, Lambert K, Hugon G, Mornet D, Mercier J. Monocarboxylate transporters, blood lactate removal after supramaximal exercise, and fatigue indexes in humans. J Appl Physiol. 2005; 98:804-9.

30. Thomas C, Bishop DJ, Lambert K, Mercier J, Brooks GA. Effects of acute and chronic exercise on sarcolemmal MCT1 and MCT4 contents in human skeletal muscles: current status. Am J PhysiolRegulIntegr Comp Physiol. 2012;302:R1-14.

31. Kim TW, Park SS, Kim BK, Sim YJ, Shin MS. Effects of sildenafil citrate on peripheral fatigue and exercise performance after exhaustive 
swimming exercise in rats. $\mathrm{J}$ Exerc Rehabil. 2019;15:751-6.

32. Green HJ, Duhamel TA, Holloway GP, Moule JW, Ranney DW, Tupling AR, et al. Rapid upregulation of GLUT-4 and MCT-4 expression during $16 \mathrm{~h}$ of heavy intermittent cycle exercise. Am J Physiol RegulIntegr Comp Physiol. 2008;294:R594-600.

33. Bishop D, Edge J, Thomas C, Mercier J. High-intensity exercise acutely decreases the membrane content of MCT1 and MCT4 and buffer capacity in human skeletal muscle. J Appl Physiol. 2007; 102:616-21.

34. Tonouchi M, Hatta H, Bonen A. Muscle contraction increases lactate transport while reducing sarcolemmal MCT4, but not MCT1. Am J Physiol Endocrinol Metab. 2002;282:1062-9. 